\title{
Do We Know More About Whorf?
}

\author{
Yanlong Wang \\ Hohhot Wendu Training School, Hohhot Inner Mongolia, China \\ E-mail: wangyanlongneida@sina.com
}

Received: 08-07-2015

Accepted: 18-10-2015

Published: 01-01-2016 doi:10.7575/aiac.ijalel.v.5n.1p.215

Advance Access Published: October 2015

URL: http://dx.doi.org/10.7575/aiac.ijalel.v.5n.1p.215

\begin{abstract}
The idea that different languages foster different world views in their speakers is part of a tradition popularized by Wilhelm von Humboldt in the 18th century long before it became associated with Whorf. In this long process, another two American linguists, Boas and Sapir, are also well-known for their great contributions to this notion. This paper tries to trace the linguistic relativity back to its origin and contextualize its diachronic developments from Europe to America. It is true, however, that it was Benjamin Lee Whorf, the chemical engineer and fire-insurance by profession and the linguist by avocation, who had undertaken extensive research into the language Hopi during 1932-1935 and Maya in late 1930s, and it was he who went further in indicating the relationship between language and thought. As a core part of Whorf's theory complex, the linguistic relativity was once interpreted in two ways: linguistic determinism which means that language determines the way people think and linguistic relativism which implies that language influences the way people think.
\end{abstract}

Keywords: Whorf, Whorf's theory, linguistic relativity

\section{Introduction}

Linguistic relativity, also known as Sapir-Whorf hypothesis, is the claim, associated closely with the names of Humboldt, Boas, Sapir and Whorf, that language in particular that one speaks exerts great influence on the way in which he thinks, especially his classification of the reality of the world. According to this theory, people who speak language totally different from others think about the world quite differently.

The writer presents the readers with a comprehensive understanding of Whorf's notion from different perspectives by rereading Whorf's original essays (18 in total) which were compiled by linguist J.B. Carroll into an anthology after his death, and offers a panorama of Benjamin Lee Whorf's thoughts concerning language diachronically.

This paper introduces the origin of the linguistic relativity and its diachronic developments. Besides, the components of the linguistic relativity will be explicated. Specifically, the strong points and weak points of linguistic relativity are evaluated respectively. Some major interpretations of Whorfian hypothesis and some most well-known experimental researches related to Whorf's ideas will be reviewed. By writing doing those above, the writer plans to show readers the reasons why Whorf is misread, untreated. The fallacies made by Whorf himself are discovered and the writer's own understanding of Whorf will be added at the end of this paper. As a result, the writer will come to have an unbiased and reasonable interpretation of Whorf with regard to the controversial issue.

\section{Origin of Linguistic Relativity and Its Diachronic Development}

Gumperz and Levinson (1996) summarized the European tradition of language diversity. Some great thinkers such as Locke (England), Condillac (France), Herder (Germany) took interest in the intellectual significance of the diversity of language categories during the late seventeenth and early eighteenth century. Later, nineteenth-century work, especially that of Humboldt in Germany and Saussure in Switzerland and France, attached great importance to this earlier tradition and opened a new era for twentieth-century approaches. Koerner (2000, p.3) outlined the lineage of linguistic relativity tracing it as far back as to the Greek philosopher, Aristotle whose Rhetoric is worldwide well-known. His paper mentioned Humboldt who had been in close contact with North American scholars interested in American Indian languages during the 1820s and 1830s (cf. Koerner, 2000). Thus the relationship between Humboldt and American anthropological linguistics seems to be apparent. Next, introduction to the development of linguistic relativity will be made from Humboldt to American anthropological linguists Boas, Sapir and Whorf and great emphases will be laid on Whorf who drew extensively on the work of Boas and Sapir and who is generally believed to have made great contributions to linguistic relativity.

\subsection{Humboldt}

Wilhelm von Humboldt (1767-1835), the great intellectual mover and shaker in the nineteenth century language studies, linguistic philosophy, and education in general, was the first to state firmly the case for strong linguistic relativism. As Ding (2009, p. 236) pointed out, he was the originator of the linguistic relativity principle. Although he is a philosopher, 
he is especially remembered as a linguist for his greatly important devotions to the philosophy of language. In 1820 , he proposed the view which bore similarities to linguistic relativity that language is the right structure of thought. Put another way, his idea was that language embodied the spirit and character of a people. Or different languages foster different world views in their speakers. He claimed that the character and structure of a language expresses the inner life and knowledge of its speakers and that languages differ from one another in the same way and to the same degree as those who use them differ from one another. To put this simply, grammar shows the way people think, and people of different languages think differently. Humboldt's linguistic relativism, however, was only discovered and publicised many years after his death. Furthermore, as for Humboldt, some languages such as English, German, and other IndoEuropean languages were superior to other languages, and as a result, surely enough, the speakers of the most perfect languages would govern the speakers of less perfect languages ( cf. Liu, 2002, pp. 78-86; Koerner, 2000, pp. 3-4).

\subsection{Franz Boas}

Franz Boas (1858-1942), who was born and trained in Germany, imported the German intellectual tradition of Herder and Humboldt to the United States. Boas was a self-taught linguist, having never received any formal training in linguistics, but this lack of professional qualification is in fact an advantage rather than a hindrance to his work (Liu, 2002, p. 143). Lucy (1992a, p. 11) summarized Boas' contributions saying that it was he who built anthropology into a professional discipline and who devoted himself to the subfields of anthropology, including physical anthropology, social and cultural anthropology, and linguistic anthropology.

Before proceeding further, it should first of all be firmly established that Boas was indeed much imbued with Humboldtian linguistic ideas with the help of primary German archival sources, in Foley's (2001, p. 195) book, which traces the use Boas made of Humboldt's idea of language observing that the relationship between language and thought is one way: linguistic categories may express (at least partially) those of thinking, but never the other way around: linguistic categories do not determine the thought.

He also contributed greatly to the methods of descriptive linguistics, which challenged the view of linguistic superiority and inferiority. In contrast to Humboldt, Boas stressed the equal worth of all cultures and languages. He maintained that all languages could express the same ideas through different ways and language is an inseparable part of culture. He strongly opposed the view that language is the soul of a race, and proved that the structure and form of a language has nothing to do with the evolution of a race and the development of a culture.

\subsection{Edward Sapir}

Edward Sapir (1884-1939) was Boas's most outstanding linguistics student and probably the most illustrious American linguist of the twentieth century. He acknowledged the close relationship between language and thought, proclaiming that they were inextricably related so that you could not understand or appreciate the one without knowledge of the other. The passage which most clearly summarizes his views on the matter comes from his paper "The Status of Language as a Science".

Human being do not live in the objective world alone, nor alone in the world of social activity as ordinarily understood, but are very much at the mercy of the particular language which has become the medium of expression for their society. It is quite an illusion to imagine that one adjusts to reality essentially without the use of language and that language is merely an incidental means of solving specific problems of communication or reflection. The fact of the matter is that the 'real world' is to a large extent unconsciously built up on the language habits of the group.... We see and hear and otherwise experience very largely as we do because the language habits of our community predispose certain choices of interpretation. (Sapir, 1929, p. 207)

From this passage, it can be shown clearly that Boas stressed the dominant status of language in the process of communication or reflection. How people choose to interpret the world is predisposed by their language habits of the community.

\subsection{Benjamin Lee Whorf}

And so we come to Benjamin lee Whorf. There is no doubt that he was the most distinguished linguist of the great triumvirate of the Boas tradition (Foley, 2001, p.199). His scholarly achievements are closely related with his career as a fire preventer, which may start all the controversy about him. In order to have a deeper knowledge of Whorf and a much fuller understanding of his interests in linguistics, the writer resorts to the bibliographical accounts of Whorf which was written by linguist J.B.Carroll (1956, pp. 1-34). According to the bibliography, Whorf was born in Winthrop, Massachusetts, on April 24, 1897. He went to the public schools of Winthrop, through the high school, where he had a good record. After graduation from Winthrop High School in 1914, he entered the Massachusetts Institute of Technology, majoring in chemical engineering. In 1919, not long after his graduation from M.I.T., he was employed as a trainee in fire prevention engineering by the Hartford Insurance Company where he worked for twenty-two years, up to the time of his death. Avocationally, he pursued a wide variety of interests including a deep concern for the American Indian languages. During his work, the company took pride in his achievements in linguistics and anthropology. It is truly remarkable that he was able to achieve distinction in two completely different kinds of work and it is of great significance to realize that despite his "amateur" status, Whorf's work in linguistics was and still is regarded as of being superb professional quality by linguists.

From what we have discussed above, we may easily find that the career of Benjamin lee Whorf can, on the one hand, be 
described as that of a businessman of specialized talents - one of those individuals who by the application of out-of-theordinary training and knowledge together with devotion and insight can be so useful to any kind of business organization. On the other hand, his career could be depicted as that of an unusually competent and diligent research worker in several otherwise almost completely neglected fields of inquiry - the study of the lost writing system of the Mayas and the study of the languages of the Aztecs of Mexico and the Hopis of Arizona. As Lucy (1992a, p. 25) argued, most of these works were still of contemporary relevance. Whorf was at first self-taught in linguistics, but later (after 1931) he had a chance of meeting Sapir at Yale, who became his teacher later on. It was because of his interaction with Sapir and the students at Yale that Whorf began his interest in linguistic relativity principle. A mention must be made of his study of the relationship between language and thinking and cognition because of his challenging hypotheses. Like Sapir, Whorf believed that thought, inasmuch as it is a cognitive understanding of the world, is linguistically mediated: thinking contains a large linguistic element of a strictly patterned nature (Carroll, 1956, p. 66). Since linguistic patterns differ, the Principle of Linguistic Relativity naturally follows. Whorf's intensive reasoning of linguistic relativity principle will be fully discussed in the sections to come.

\section{The Strong Hypothesis and the Weak Hypothesis}

As is stated above, the notion that thought is shaped by language is commonly known as the Sapir-Whorf Hypothesis or Whorfian Hypothesis, "to acknowledge the role of Whorf's mentor" (Carroll, 2008, p. 396). It must be noted that compared with its another name, linguistic relativity principle, the term Sapir-Whorf hypothesis does not date back that far, however. Some scholars tend to believe that this term was perhaps used by Harrry Hoijer in 1954 in a paper at a conference, but was soon made more widely known through J.B.Carroll's posthumous edition of Whorf's essays in 1956.

In the years to follow, the so-called Whorfian Hypothesis was interpreted in a number of ways. The idea that lies at the center of the hypothesis is that a man's language moulds his perception of reality. We see the world in the way that our language describes it, so that the world we live in is a linguistic construct (cf. Liu, 2002, p. 158). In traditional scholarship, psychologists have concluded that the Sapir-Whorf hypothesis has two major components: linguistic determinism and linguistic relativity. The former is a claim that the language we speak determines the nature of our thoughts, including the types of ideas and concepts we have and the latter is a claim that language influences thought. It suggests that language has a more ingenious effect on thought and only influences what we possibly perceive and remember about an object. The two versions have also been labeled 'strong' and 'weak' (Brown, 1976). As Lee (1996, p. 85) claimed, the notion is taken for granted that there is a strong or deterministic version of linguistic relativity principle extractable from Whorf's descriptions and another weak version. And the overwhelming consensus is made that it is out of the question to test the strong hypothesis, which has aroused heated debate in disciplines as varied as philosophy, education, anthropology, psychology, and the new cognitive science, as well as linguistics. Consequently, the problem of the relation among language, thought and reality has been haunting the researchers in these domains. Before listing the tests or experiments of the empirical studies of Whorfian Hypothesis in the next section, the writer decides to give a full representation of the two versions of Whorfian Hypothesis and put aside the various debates for its truthfulness or falseness.

\subsection{The Strong hypothesis}

The strong version of the linguistic relativity is that one's thinking is entirely determined by his language in that one can realize the world in terms of the categories and distinctions which are encoded in the language. Sapir once said that human beings are greatly influenced by the particular language functioning as the medium of expressions for their society (Sapir, 1929, p. 207). His student Whorf added depth to these ideas. He went much further than saying that there was a milder assertion that language affects people's way to look at the world, in Whorf's view, the relationship between language and world was a deterministic one (Wardhaugh , 2000, p. 217). One of the strongest statements by Whorf concerning his ideas is as follows:

The background linguistic system (in other words, the grammar) of each language is not merely a reproducing instrument for voicing ideas but rather is itself the shaper of ideas, the program and guide for the individual's mental activity, for his analysis of impressions, for his synthesis of his mental stock in trade. Formulation of ideas is not an independent process, strictly rational in the old sense, but is part of a particular grammar, and differs, from slightly to greatly, between different grammars. We dissect nature along lines laid down by our native languages. The categories and types that we isolate from the world of phenomenon we do not find there because they stare every observer in the face; on the contrary, the world is presented in a kaleidoscopic flux of impressions which has to be organized by our mind. We cut nature up, organize it into concepts, and ascribe significance as we do, largely because we are parties an agreement to organize it in this way - an agreement that holds throughout our speech community and is codified in the patterns of our language. The agreement is, of course, an implicit and unstated one, but its terms are absolutely obligatory; we cannot talk at all except by subscribing to the organization and classification of data which the agreement decrees. (Carroll, 1956, pp. 212-14)

From the above statements, we see that there are several notions lying behind them. One is that languages determine reality in different ways. Another is that the differences of the languages are surely covert, implicit, or unconscious; as the users of the languages, we are unaware that in what ways we cut nature up. Last but not least, our worldview is 
affected by these linguistic differences.

Although this viewpoint is a deterministic one, Whorf actually twice uses the word largely, which implies that he does not go all the way to claim that the structure of a language entirely determines the way in which the speakers view the world. However, he continues:

This fact is very significant for the modern science, for it means that no individual is free to describe nature with absolute impartiality but is constrained to certain modes of interpretation even while he thinks himself most free. The person most nearly free in such respects would be a linguist familiar with very many widely different linguistic systems. As yet no linguist is in any such position. We are thus introduced to a new principle of relativity, which holds that all observers are not led by the same physical evidence to the same picture of the universe, unless their linguistic backgrounds are similar, or can in some way be calibrated. (ibid, p. 214)

In my understanding here, Whorf expressed a relatively mild idea that there was no such strict standard by which people carve the nature except when those especially the linguists are familiar with a variety of different languages. Given the background of the users' linguistic usage, people from different cultures may possibly have different understandings towards the same thing. Whorf still emphasized language more, for him, if the languages they use differ in structure, the different speakers will certainly experience a different world. If language were the only factor in the interpretation of the world, the picture would be what Whorf had claimed.

\subsection{The Weak hypothesis}

Now it is high time that we shifted our attention from the linguistic determinism to linguistic relativity. It was in the paper "Science and Linguistics" that Whorf first used the term "linguistic relativity principle" which implies that the categories and distinctions encoded in one language system are unique to that system and incommensurable with those of others. Whorf, like his tutor Edward Sapir, believed that language classifications influenced thought. Whorf argued that the perceptual events that people experience can be very different from those experienced by speakers of other languages. When looking at the rainbow, a majority of English speakers can recognize red, orange, yellow, green, blue, and purple. But Whorf said that the colour people perceive comes from the colour naming influence of language. Across the world some languages do not divide the colours into the same number of basic categories. One language may not tell the difference between green and blue, and the speakers of that language will not depict the rainbow in the same way as English speakers do. According to Whorf, people's different categories and concepts in different languages show the different ways of the speakers' abilities to categorize and analyze the world, which is supported with a typical example from the Hopi language in which the speakers talk about clouds in their rain prayers as if they were alive. Whorf pointed out that from this alone, an ethnographer cannot tell whether this sort of expression is some metaphor or special religious or ceremonial figure of speech or whether the Hopi speakers treat clouds as living is an ordinary way of thinking. Actually, the Hopi speakers distinguish an animate class of nouns as a crytotype. They pluralize the word cloud in an animate way and do believe clouds to be alive (Carroll, 1956, p. 79).

By reading Whorf's original works, we notice that his main analyses of his topic concerning the relationship between language and thought can be seen in his following papers: "Science and Linguistics", "Linguistics as an Exact Science", "Languages and Logic", "Language, Mind, and Reality". Together with his previous essay "The Relation of Habitual Thought and Behaviour to Language," these five essays give Whorf's central treatment of linguistic relativity principle. Special attention is drawn to the paper "The Relation of Habitual Thought and Behaviour to Language," in which Whorf highlighted his concerns, gave a full account of the theoretical foundations of the principle, and provided empirical evidence in support of his arguments. Let us begin by citing some examples to show that language influences thought. Whorf's exemplification can be generally divided into lexical and grammatical categories.

\subsubsection{Lexical examples}

Whorf noted that in the American Indian language of Hopi, just one word covers everything that flies except birds (for example, the same word for insects, airplanes, aviators, and so on). The same name is used to cover all these separate objects by the Hopi speakers and interestingly it is not difficult for them to do so. Whorf argued that though this class might be extremely broad to us, so would our class snow to an Eskimo.

We have the same word for falling snow, snow on the ground, snow packed hard like ice, slushy snow, wind-driven flying snow-whatever the situation may be. To an Eskimo, this all-inclusive word would be almost unthinkable; he would say that falling snow, slushy snow, and so on, are sensuously and operationally different, different things to content with; he uses different words for them and for other kinds of snow. (Carroll, 1956, p. 216)

Whorf maintained that there is no so called natural way to dissect nature; the speakers from entirely different linguistic background do it in quite different ways. Although his descriptions of Eskimo snow word met with opposition, turning to his works, he did not emphasize what might cause the differences between Eskimo and English in terms of the word snow. Rather, he did believe that these differences of languages would lead to differences in thinking.

Whorf gave another example from his work experience in which he tried to explain why fires were caused. Initially, he thought that it was purely because of the physical conditions that led to the start of fire, such as presence or lack of air 
spaces between metal flues and woodwork. As time went by, he realized that a physical situation was not a decisive factor, but the psychological causes were of importance: the implied meaning of a situation to an individual often was closely associated with the onset of the fire from time to time. And the implied meaning was frequently expressed in the form of linguistic meaning, such as the meaning typically conveyed by particular words:

Thus, around a storage of what are called "gasoline drums," behaviour will tend to a certain type, that is, great care will be exercised; while a storage of what are called "empty gasoline drums," it will tend to be different - careless, with little repression of smoking or of tossing cigarette stubs about. Yet the "empty" drums are perhaps the most dangerous, since they contain explosive vapour. Physically the situation is hazardous, but the linguistic analysis according to regular analogy must employ the word "empty," which inevitably suggests lack of hazard. (Carroll, 1956, p. 135)

Whorf provided this example as evidence of the power of the words to affect thought process. For his part, people are careless due to the word empty. Believing that the drums are empty tends to lead to such careless behaviour as having cigarettes around them. But empty drums are possibly the greater hazard, containing highly explosive vapor. Physically, the situation is dangerous, but, Whorf pointed out, the English speakers are led to have such an understanding of the same word empty: 1) as a virtual synonym for 'null and void, negative, inert,' 2) applied in analysis of physical situations without regard to, e.g., vapour, liquid vestiges, or stray rubbish, in the container. Whorf believed the word empty was meant in the sense of (2), but was understood by speakers in the sense of (1), undoubtedly, with catastrophic consequences. Lucy (1992a, p. 50) diagramed this example, shown in the following manner.

Diagram of one of Whorf's fire-causing examples:

Linguistic form

Linguistic meanings

container no longer

contains intended contents

null and void

Mental interpretations

drum is no longer

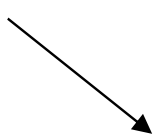

negative, inert

Nonlinguistic observables

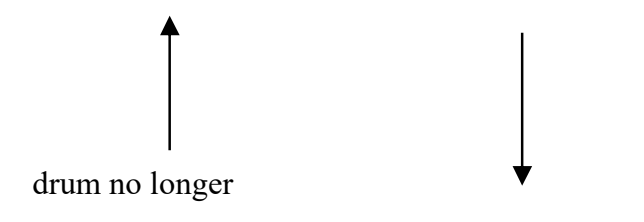

drum no longer

contains gasoline

dangerous; $\mathrm{OK}$ to
smoke cigarette

smoke cigarette

smoke cigarette

smoke cigarette

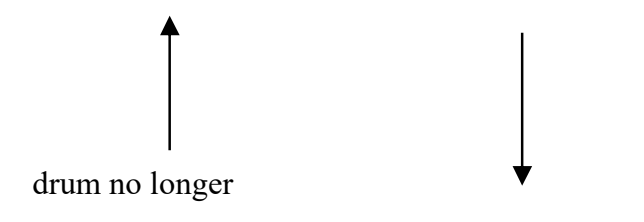

However, a point to note is that Whorf here used the word "regular", which demonstrates that we come to the interpretation of reality or experience on the basis of habitual experience or thought with words. That is also the point where people misunderstand him just because of the wrong explanation of his wording: regular. Moreover, Whorf presented his evidence mainly from his comparisons between the Hopi language and English. Apart from the lexical differences between them, Whorf seemed to take more interest in the grammatical differences

\subsubsection{Grammatical examples}

Whorf argued that words in English and other European languages are divided into two major categories: nouns and verbs. This distinction may lead speakers of English to think that the world is also divided in two categories: actions and objects. As a result, they even treat something abstract and shapeless as an object (Carroll, 1956, pp. 139-140). For example, time is a continuum; English speakers regard it as something divisible and countable. Thus they have the concepts of "five minutes" or "six hours". But in Hopi, words are not classified in the same way as the English words are. Instead of saying "three days", the Hopi speakers say "dayness the third time" or "the third dayness". His contrastive analysis of the grammar was such that the Hopi language was a time-less language in that he could find no clear grammatical structure to distinguish past, present and future (Carroll, 1956, p. 57). In English, however, the verb structure obviously shows the tense. This was just one indication of how grammatical features vary greatly from 
language to language.

Whorf also offered another example of grammatical distinctions. In English, there is a distinction between individual nouns and mass nouns, a distinction more commonly and frequently referred to by some as the distinction of count nouns and mass nouns. He defined the English terms as follows:

We have two kinds of nouns denoting physical things: individual nouns, and mass nouns; e.g., 'water, milk, wood, granite, sand, flour, meat.' Individual nouns denote bodies with definite outlines: 'a tree, a stick, a man, a hill.' Mass nouns denote homogenous continua without implied boundaries. (Carroll, 1956, p. 140)

It has been known to all English learners (even if he or she is a novice) that the distinction is that individual nouns or count nouns take the plural form, whereas mass nouns cannot. Therefore, we can say, tables, flowers, but not coffees, milks. What is more, singular nouns have the form of obvious linguistic markers such as indefinite article $a$ or an, but mass nouns do not. In contrast, in Hopi, there are no mass nouns. Obviously, the Hopi speakers never use those linguistic devices to express the mass nouns as the English speakers do.

Although English mass nouns cannot be pluralized in a direct way, their plural forms can be realized with the help of a phrase of the form: count noun + of + mass noun. In terms of what kind of nouns should be selected in order to fulfill the requirement of the phrase, Whorf argued that such "linguistic devices" included the names of body types and the name of containers, for instance, the expression a slice of meat belongs to the former and the one a glass of juice belongs to the latter. Thus, even though we cannot say juices or meats, we can say a glass of juice, or a piece of meat respectively. Only in this way can mass nouns be individualized. Notice that Whorf put these two distinct types of experience: body and container under the same grammatical pattern. Through his analyses with great care, we are therefore guided to have a more comprehensive knowledge of that. The grammatical pattern count noun + of + mass actually denotes two meanings, an obvious one: a container and its contents, like a glass of juice; and an inobvious one like a slice of meat without such a relationship but can be explained in the same way. In Whorf's own words: the formulas are very similar (Carroll, 1956, p.141). According to Whorf, this form of expression has cognitive consequences because it leads us to think of some objects as being "containers"(form) that hold "contents"(substance or matter). And the English speakers may have some exceptions. For example, even though some objects, such as butter and meat, have clear boundaries, generally, count nouns are thought to have clear outlines or boundaries, but mass nouns are not, they are treated grammatically as mass nouns (for example, two bars of chocolate, not two chocolates). Thus, Whorf suggested that English speakers think of objects as consisting of form and substance because of this grammatical distinction.

Those cited above are just some of Whorf's empirical study of the relationship between language and thought.

\subsection{Evaluation of the Strong hypothesis}

The strong version of Whorfian Hypothesis has been criticized on a number of grounds. To begin with, Whorf's argument is circular (Lenneberg \& Robberts, 1956). He claimed that thought is different just because language is different. To test their relationship, we may assume that if there is a correlation between language and thought, any one of them must be identifiable. However, Whorf never studied thought and all his research work focused on language alone. For instance, he nurtured the belief after his careful analysis of Hopi that Hopi's concept of time which is totally different from that of the English speakers is just Hopi's expression of the idea in a special way. In other words, there must exist great differences in thought because he had found differences between the two languages. However, some scholars hold a different attitude, arguing that people can also account for the phenomenon that English differs from Hopi as such: the thoughts determine their linguistically structural differences. Surely enough, this dispute never comes to an end. Thus, at this juncture, we must make it clear that some non-linguistic factors are actually involved in the process of thought and then the link between language and thought is likely to be established. This argument may possibly make untrue his claim that the differences in thought are determined by the linguistic differences.

In addition, Garnham and Oakhill (1994) believed that Whorf's use of "evidence" concerning the different number of words for snow used in Eskimo and English is flawed. They argue that the reason for which the speakers with different linguistic backgrounds need the different numbers of words is that the environment is the decisive factor instead of the fundamental differences in thought. I commit to the notion that environment must be taken into account when considering different expressions denoting the same meaning. For example, 东风 in Chinese and west wind in Great Britain share the same meaning "favourable conditions". Does this reflect the difference in thinking between the two nations? Of course not, the different usage is just a demonstration of the different geographical locations. England is an island located in Atlantic Ocean, and she has got a special climate which is different from that in China. Those are the methodological problems to be solved before any conclusion can be reached in line with linguistic determinism. Therefore, "the strong version of Whorfian hypothesis does not seem to be a plausible theory" (Tohidian, 2009, p. 69). Third, the criticism is concerned with the embarrassment of translation. Garnham and Oakhill (1994, p. 48) described how Whorf translated native American language into English in a "simplistic, word-for-word" way. When this overliteral translation is applied, we may misunderstand the thought of other people. Take the English sentence "He often robs Peter to pay Paul" for example, any literal translation is certainly strange. If we translate the sentence into "He often robs Peter of his money to return the money that he borrows from Paul", we readily find that the meaning is superficially faithful but essentially misleading.

When it comes to the recent studies of Whorf's linguistic relativity principle's influence upon translation, House (2000, 
p. 73) points out that Whorf's work is only concerned with the vastly different languages between SAE and American Indian languages, it is relatively easy to list many other examples of grammatical diversity among the languages across the world. For example, the category of number is not obligatory in Chinese; Fijian has four-way number system for personal pronouns (singular, dual, paucal, multiple) but no number at all for nouns and so forth. House expressed his crux of translatability in the following:

Now if languages display such striking grammatical differences, and if — as Whorf maintains - linguistic form has truly "tyrannical hold" upon our way of thinking and perceiving, one might conclude that the theoretical possibility of translating, not only from and into SAE and American Indian languages, but also from and into many other languages, seem to be denied. (House, 2000, p. 73)

Is the fact really so? If Whorf is right, the relativity principle will surely hinder the development of translation. According to Whorf's view, a translation whose form is totally different from its original would no longer be a translation, but a "transfiguration" (House, 2000, p. 74). Obviously, cultures across the world will never stop their development just because of the barriers in translation. Thus, if some individuals persist in using Whorf's principle in translation, it will undoubtedly impede the advance of communication among different cultures.

My understanding is that if the strong version the Hypothesis is credible, it may result in some conclusions. For example, if language determines thought, we may say that thought does not exist without language. According to my observation, a 15- month-old boy cannot express his ideas, but he can comprehend the basic linguistic input, and respond to what he is instructed to do. Interestingly, if we treat language as the decisive factor in moulding thought, we may control someone's thought by analyzing his or her process of studying his or her native language. This, however, seems impossible to perform.

\subsection{Evaluation of the Weak hypothesis}

Some studies were conducted to test the credibility of the weak version of Whorfian Hypothesis. The studies by Berlin and Kay (1969) and Heider (1972) and were very influential and together with many others, they did not regard the weak version of linguistic relativity as a credible theory for some time. The consensus made among the studies was that colour grouping is universal and inconsistent with the linguistic relativity. There are several problems with respect to the debate. From the linguistic relativity principle, we come to understand that language might not be the sole factor to mould thinking mode. However, it just affects how people view the world. Thus, the question arises: to what extent does language shape our thought? And then, besides language, is culture another factor in influencing people's thought? It is universally acknowledged that when using a different language, one is applying a different set of social values or cultural norms in terms of the account of the same object or phenomenon, which may point to such a fact that except for the linguistic factor, the cultural factor may also exert influence on people's thought. The American linguist Charles Hockett (1954) said that languages differ not so much as to what can be said in them, but rather as to what it is relatively easy in them (p. 122). By making it relatively easier to say certain things than others, a language helps to reinforce certain ideas and beliefs, enabling them salient, pushing them into the foreground of the users' attention. But why is it that certain ideas are pushed into the foreground of attention while others are kept in the background? And why is it that languages differ in the things they make salient? Whorf was not very much concerned with these questions (Liu, 2002, p. 165). Thus, one of the problems of the weak version of the linguistic relativity is that it is not easy to understand precisely what the theory is and what should be tested in the experiment. As Lee (1996, p. 85) noted, some researchers hold the view that the weakest interpretations were of no interest theoretically, among whom was Lucy (1992a).

\section{People's Misunderstanding and My Understanding}

Despite the significance of his work, Whorf has frequently been misunderstood by his contemporaries and the following researchers as well. And his theories were proved to be untrue and even denigrated sometimes because of people's superficial readings of his work or lack of familiarity with his primary documents and unpublished writings. The goal in this section is to work through Whorf's writings to rectify some of the prevalent misunderstandings.

\subsection{Misunderstanding and my understanding}

Because Whorf died young, only 44 years old, he was unable to form a systematic theory concerning his research interest, hence the unavoidable misunderstanding toward his ideas. Firstly, some scholars hold the view that there is a clear cut between the strong point and weak point of Whorfian Hypothesis. By reading his original work, we may find that Whorf did not make such a distinction. In the previous section, Whorf's notion of linguistic relativity has been presented in detail and it is obvious that he never put forward a definite concept that language determines thought completely. Just like what Yao Xiaoping (2002, p. 77) has depicted, Whorf sometimes favoured the weak version of linguistic relativity, but sometimes the strong one. With these, I conclude that dividing the Whorfian hypothesis into two versions seems to have yet to prove its rationality. In his paper "The Relationship of Habitual Thought and Behaviour to Language", Whorf pointed out that "I should be the last to pretend that there is anything so definite as 'a correlation' between culture and language". It is easy to see that Whorf would like to investigate more to find the relationship between language and thought. In another paper "Linguistics As an Exact Science", he claimed that science of course was not CAUSED by this grammar; it was simply coloured by it (Carroll, 1956, p. 221). We may probably say that the weak version may derive from this relatively reconciled assertion. With respect to the strong hypothesis, it has been elaborated tensely, there is no need here to say again. In a word, Whorf never had a systematic 
account of his theory in this aspect but mentioned this in some isolated segments of sentences or paragraphs.

Secondly, from the strong view that language determines thought, we may question how thought is defined here, thereby bringing about another misunderstanding: Does language determine the habitual thoughts or the creative thoughts or anything else? From Whorf's essays, I argue that here language determines the habitual thoughts because we do not find anything which is related to the "specialized thoughts" or "potential thoughts" (Lucy, 1992a, p. 7). What is habitual thought? According to Lucy(1992a, p. 7), it is meant everyday, routine ways of attending to objects and events, categorizing then, remembering, and perhaps even reflecting upon them. It is not hard to see that Whorf's examples or data come mainly from the common Hopi or English languages. If researchers pay attention to any except the habitual thought, the view that language determines thought may turn out to be an entirely wrong conclusion.

\subsection{Reasons for the misunderstanding}

The writer here agrees with the generally accepted view that the Whorfian hypothesis's true value lies in the discovery of the relationship between language and thought, which brings an end to the traditional idea that language is attached to thought. Thus, language acquires its dominant status. However, it is a great pity that Whorf, in the process of his argument toward this issue, just focused on such American Indian languages as Hopi, and selected some examples with the intention of uncovering the true nature of that language. He did not explain why he did so, and consequently, his selection of examples seemed not to be scientific, typical or systematic. What's more, his failure in the logic might also lead to some defect. In his bibliographer, Carroll's own words, he was more interested in what, in some abstract sense, was being thought about than with the mental process by which one might think (Carroll, 1956, p. 26). That is, he just kept an eye on linguistic factors in terms of thinking, not the nonlinguistic ones. Apart from these, some other reasons for those misunderstandings will also be taken into account.

Despite the fact that Whorf is so often mentioned in such a wide range of disciplines with respect to the hypothesis named after his name, noticeably little attention has been given to his matrix of the theory in which linguistic relativity is just part of it. Put another way, some researchers just concern with Whorf's linguistic relativity and neglect his overall theoretical systems. As a result, Whorf's ideas were and still are treated partially, not as a whole. Within Whorf's short lifetime, few of his colleagues or contemporaries have realized the range and conceptual versatility of his thinking or of the nature of his early work. His ideas were to a certain degree unconventional so that Whorf was always prudent about his statements and claims to someone else about his work, which might result in a failure of his writings' publication.

In addition, Whorf's work has seldom received criticism which I think is an essential part for one's academic research, from his professional peers or the following scholars. This can be found from the fact that so few of the articles in the anthology are regularly quoted.

It is obvious that people's misunderstanding of Whorf lies in the fact that his failure to give a full account of his theory in his writings may cause confusion. So the researchers may face such an impediment to appreciating the subtlety, detail, and revolutionary significance of his ideas. Furthermore, Whorf never published even a monograph, and the only way we can have access to his ideas is through his individual papers or the collection of papers whose topics are not consistent with one another. That is to say, it is hard to obtain the systematic and comprehensive explanation in view of one theme.

As is known to all, Whorf is a chemical engineer by training, a fire prevention engineer by vocation, and a linguist by avocation. His research was involved in the business activities which left him relatively little time to work on his linguistic study. Even though he had done a lot in the field of linguistics, it is possible that he could not synthesize all his viewpoints of his thinking and explicate them as an integrated theory. It is also a great pity that people have no access to his unpublished writings. Consequently, lack of information about Whorf has stopped people from being able to grip with the intent and focus of his thinking. The reasons for this can be concluded as follows: Whorf's personal circumstances; historical or cultural contingence of his own time; some scholars' research interest and emphases, all of which can contribute to the phenomenon that Whorf's writings cannot be read widely.

Some scholars worried that Whorf's certain aspects of research can fall into such categories as "religious" because he admired immensely the philologist Antoine Fabre d'Olivet (1768-1825). Apart from the fears of scholars, his background in physical science has also made some of his arguments and statements hard to be understood by a number of readers. However, a fact cannot be ignored that it was because of his physical science background that he could form his theoretical foundations and carry out all his linguistic investigations. Another point to note is that in his writings, Whorf's use of such terms as cryptotype and phenotype as alternates to the terms covert and overt, which can be confusing for many readers. Whorf sometimes used those terms as if they were equal to the terms overt and covert, however, in his other papers, he used them to denote the subsets of the terms. Specifically, he used phenotype and crypotype more exclusively for meaning contrasted to marking, but this was different from his earlier uses:

Grammatical classes which appear ordinarily "without" markers do have markers appearing with them under certain particular circumstances---such a class is "covert", and its marker a "reactance". Its grammatical meaning, if distinguishable, is a "cryptotype"... Overt categories are accompanied by markers in all or nearly all sentences... Their grammatical meanings are "phenotype". (quoted in Lucy, 1992a, p. 28) 
directed to him.

As Lee (2000) noted, the scholars including Lucy, Lee, Gumperz and Levinson all uncovered a "curious anomaly", that is, when researchers in the past set about studying Whorf, his definitions of what he dubbed the linguistic relativity principle seldom appeared in their theoretical discussions of his idea as starting points. Besides, his definitions were not taken as foundational in empirical work.

\section{Conclusion}

The Whorf hypothesis claims that our language shapes the way we think about the world. The hypothesis is made up of two parts, one is linguistic determinism and the other is linguistic relativity. The former maintains that languages determine the way we think of the world while the latter states that languages influence the thought. Whorf himself did not give a full account of the theory and did not provide convincing evidence for his hypothesis. There is some evidence for Whorf hypothesis both at the lexical level and the grammatical level. But the cognitive linguistics seems to provide more support for the hypothesis. Whorf's statement about linguistic relativity has actually intrigued a number of disputes and they seem never to come to an end.

\section{References}

Berlin, B. \& Kay, P. (1969). Basic colour terms: their university and evolution. Berkeley: University of California Press Brown, R. W. (1976). In memorial tribe to Eric Lenneberg. Cognition, 4, 125-153

Brown, R. W., \& Lenneberg, E. H. (1954). A study in language and cognition. Journal of abnormal and social psychology, 49, 454-462.

Carroll, D. W. (2008). Psychology of language. Beijing: Foreign Language Teaching and Research Press.

Carroll, J. B. (Ed.). (1956). Language, Thought, and Reality: Selected writings of Benjamin Lee Whorf. Cambridge, MA: MIT press.

Ding, Y. R. (2009). A western philosophy of language: A guide for students of linguistics. Shanghai Foreign Language Education Press.

Foley, W. A. (2001). Anthropological linguistics: An introduction. Beijing: Foreign Language Teaching and Research Press.

Garnham,A. \& Oakhill, J. (1994). Thinking and reasoning. Oxford: Blackwell.

Gumperz, J. J.,\& Levinson, S. C. (1996). Rethinking linguistic relativity. Cambridge, U.K.: Cambridge University Press. Herder, E. R. (1972). Universals in colour naming and memory. Journal of Experimental Psychology, 93, 10-20.

Hockett, C. F. (1954). Chinese versus English: An exploration of the Whorfian theses. In H. Hoijer (Ed.), language in culture (pp. 106-123). Chicago: University of Chicago Press.

House, J. (2000). Linguistic relativity and translation. In M. Putz \& M. H. Verspoor (Eds.), Explorations in linguistic relativity (PP. 69-88). Amsterdam: John Benjamins.

Koerner, E. F. K. (2000). Towards a 'full pedigree' of the 'Sapir-Whorf hypothesis': From Locke to Lucy. In M. Putz \& M. H. Verspoor (Eds.), Explorations in linguistic relativity (PP. 1-24). Amsterdam: John Benjamins.

Lee, P. (1996). The Whorf theory complex. Amsterdam and Philedelaphia: John Benjamins.

Lee, P. (2000). When is 'linguistic relativity' Whorf's linguistic relativity? In M. Putz \& M. H. Verspoor (Eds.), Explorations in linguistic relativity (PP. 45-68). Amsterdam: John Benjamins.

Lenneberg, E. H. \& Roberts, J. M. (1956). The language of experience. Memoir 13, University of Indiana Publications in Anthropology and Linguistics.

Liu, R. Q. \& Feng, Z. X. (2002). The theories and schools of linguistics. Nanjing: Nanjing Normal University Press.

Lucy, J. A. (1992a). Language diversity and thought: A reformation of the linguistic relativity hypothesis. Cambridge, U.K.: Cambridge University Press.

Sapir, E. (1929). The study of language as a science. Language, 5, 207-214

Tohidian, I. (2009). Examining linguistic relativity hypothesis as one of the main views on the relationship between language and thought. Psycholinguist Res, 38, 65-74.

Wardhaugh, R. (2000). An introduction to sociolinguistics. Beijing: Foreign Language Teaching and Research Press. Yao,X.P. [姚小平], 2002, 人类语言家沃尔夫的遗产一读《论语言、思维和现实》, 《外语教学与研究》(1): 7577. 